\title{
Nursing students' grit: a cross-sectional study
}

\author{
Kang Se-Won \\ Dongseo University, \\ Department of nursing, Sasang-gu, Busan, South Korea
}

\begin{abstract}
This descriptive study aimed to investigate the grit of nursing students. Participants were 273 students from two nursing departments in South Korea. Data were collected from March to August 2018. Data were analysed using mean, standard deviation, the independent samples t-test, and analysis of variance (ANOVA), using the IBM SPSS Statistics 22.0 program. The grit score of the nursing students was 3.27 (out of 5), and those on the sub-factors consistency interest and perseverance of effort were 3.13 and 3.40 out of 5, respectively. Grit scores differed significantly according to gender. Males tended to show higher scores than females on grit $(t=4.684, p<0.001)$ and on the subfactors consistency interest and perseverance of effort $(t=3.922, p<0.001 ; t=3.978$, $\mathbf{p}<\mathbf{0 . 0 0 1}$, respectively). It is therefore necessary to find ways to increase the grit of female students. Research on grit in college students needs to continue.
\end{abstract}

Keywords: nursing; students; grit; gender

\section{INTRODUCTION}

In recent years, grit, which has been of interest to many researchers in South Korea, has been evaluated as an attribute related to individuals' success [1]. Introduced by Duckworth, Peterson, Matthews, and Kelly [2], the concept of grit is based on positive psychology, which focuses on growth and development through individuals' strengths. It is defined as a passion and commitment to long-term goals.

Grit consists of two sub-factors, consistency of interest and perseverance of effort [3]. Consistency of interest refers to the degree of passion and to the extent to which one goal or interest is maintained over a relatively long period. In contrast, perseverance of effort pertains to the patience and perseverance to overcome obstacles and difficulties [4]. In other words, grit refers to the enthusiasm to overcome difficulties and make enduring efforts to achieve goals. A person with strong grit, regardless of changes in circumstances, strives constantly to achieve one's goal [5].

Research on grit in nursing students in South Korea is at the beginning stage, and several studies have been conducted in the recent past. In previous studies, the grit of nursing students was found to be influenced by various factors. Further, studies have examined academic resilience and psychological well-being [6]; stress and adaptation to college life [7]; selfleadership and college life adjustment [8]; and academic stress, academic self-efficacy, and major satisfaction [9] in relation to grit. However, there is still a lack of basic research on various variables.

For nursing students, grit is considered a positive mental force that is necessary for transforming them into a medical professional. It is represented by characteristics such as tenacity, commitment, passion, and patience. Therefore, appropriate interventions to improve nursing students' grit levels would not only help them succeed in college but they would also 
help them to serve as professional nurses after graduation. Accordingly, research on grit in nursing students is necessary for in-depth discussions on the use of grit for their development.

\section{Study purpose}

This study aimed to understand the level of grit of nursing students. The specific objectives were as follows:

- To investigate the degree of grit in nursing students.

- To investigate the differences in grit levels according to the general characteristics of nursing students.

\section{Study Design}

METHODS

This descriptive study employed a cross-sectional design to investigate the grit of nursing students.

\section{Participants and data collection procedure}

Participants were 273 students from two university nursing departments in Korea. Data were collected from March to August 2018.

The sample comprised 44 (16.1\%) males and 229 (83.9\%) females. Further, 69 (25.3\%) of them were in the first grade, $61(22.3 \%)$ were in the second grade, $70(25.6 \%)$ were in the third grade, and $73(26.7 \%)$ were in the fourth grade. Among the 3rd and 4th grade students, $130(47.6 \%)$ had clinical practice experience (Table 1).

\section{Ethical considerations}

This study conformed to the ethical principles for research with humans. For the ethical protection of the participants, before the questionnaire was distributed, the purpose of the study was explained and the questionnaire was provided only to those who voluntarily submitted written consent.

\section{Measurement}

\section{Grit}

Grit was assessed using the Short Grit Scale (Grit-S) developed by Duckworth and Quinn [3], who provided the permission to use the tool in this study. This tool comprises 8 items with 2 sub-factors; 4 items each on 'consistency of interest' and 'perseverance of effort'. Each item is rated on a 5-point Likert scale ranging from 1 point for 'not at all' to 5 points for 'very strongly'. Four negatively worded items were reverse coded. Higher scores on this scale indicate higher levels of grit. The reliability of the instrument was Cronbach's alpha $=0.785$ in the present study.

\section{General characteristics}

The general characteristics of the participants included grade, gender, and clinical practice experience.

\section{Data analysis}

The collected data were analysed using IBM SPSS Statistics 22.0. Degree of grit was analysed using descriptive statistics (frequency, percentage, mean, and standard deviation). Differences in the grit score according to the general characteristics of the participants were analysed using an independent samples t-test and analysis of variance (ANOVA). Statistical significance was declared at $\mathrm{p}=0.05$. 


\section{Participants' grit score}

RESULTS

The mean grit score was $3.27 \pm 0.58$ (out of 5 ), and that on the two sub-factors, consistency interest and perseverance of effort, was $3.13 \pm 0.70$ and $3.40 \pm 0.65$ (out of 5), respectively. Among the 8 items on the Grit-S, the highest score was 3.56 0.89 , for the item 'I am a hard worker' (Table 2).

\section{Differences in grit score according to participants' general characteristics}

The results for the comparison of grit scores according to participants' characteristics have been shown in Table 3. With reference to gender, the average grit score was higher for males than for females (3.63 vs. $3.20, \mathrm{t}=4.684, \mathrm{p}<0.001$ ). Male also scored higher than females on both sub-factors (consistency interest: 3.51 vs. 3.06, $t=3.922$, $\mathrm{p}<0.001$; perseverance of effort: 3.75 vs. $3.33, t=3.978, p<0.001$ ). There was no significant difference in the mean grit scores or those on the sub-factors according to grades and clinical practice experience.

\section{DISCUSSION}

This cross-sectional study attempted to identify the grit of nursing students. The mean grit score of the participants was 3.27 out of 5 , which was slightly higher than the median. These results are similar to those of Jin and Kim [6], who studied the grit of nursing students. They found a mean score of 3.02 on grit and that of 2.76 and 3.28 on the two sub-factors of consistency interest and perseverance of effort, respectively. Note that consistency interest was lower than perseverance of effort. Persistence of interest pertains to the ability to stick to one goal for a long period [10]. These results show that it is difficult for students to focus on the same goal for a long time. Duckworth [10] stated that perseverance of effort is possible when consistency interest is supported. Thus, students' grit may improve if they apply individual goal-setting strategies that can sustain their long-term interest in the goal.

The average grit score was higher in males than in females. However, previous studies have reported varying results. For instance, Kang's study [8] on nursing students showed that grit scores were higher among males. However, there was no difference in grit according to gender in a study on elementary, middle, and high school students conducted by Kim, et al. [11]. In Lee's study [12] of community college students, perseverance of effort and consistency interest were significantly higher in males and females, respectively. The present results found that females scored lower on grit. Therefore, it is important to identify ways to increase the grit of female students.

There was no significant difference in mean grit scores according to grade and clinical practice experience. These results are similar to those of Jung and Jeong [9]. Evidently, it is necessary to develop curricular and extra-curricular activities to improve nursing students' grit. Further, by analysing factors influencing grit, it is necessary to establish an environment that aids the continuous development of grit in students, which in turn will enable them to complete tasks successfully.

\section{Limitations of the study}

The present results should be interpreted carefully owing to the use of convenience sampling in selecting the participants.

\section{CONCLUSION}

This study investigated the grit of nursing students. Male nursing students had higher grit scores than female nursing students did. It is therefore necessary to find ways to increase the grit of female students. Additionally, it is necessary to analyse various factors affecting grit in nursing students. 


\section{References}

Lim, H.J. An exploratory study on grit's factor structure and its validity. Asian Journal of Education, 2017. 18(2): p. 169-192.

Duckworth, A.L., et al., Grit: perseverance and passion for long-term goals. Journal of Personality and Social Psychology, 2007. 9: p. 1087-1101.

Duckworth, A.L., and Quinn, P.D. Development and validation of the short grit scale (Grit-S). Journal of Personality Assessment, 2009. 91(2): p. 166-174.

Duckworth, A.L., and Seligman, M.E.P. Self-discipline outdoes IQ in predicting academic performance of adolescents. Psychological Science, 2006. 16: p. 939-944.

Salles, A., Cohen, G.L., and Mueller, C.M., The relationship between grit and resident well-being. American Journal of Surgery, 2014. 207(2): p. 251-254.

Jin, J.I., and Kim, N.C. Grit, academic resilience, and psychological well-being in nursing students. The Journal of Korean Academic Society of Nursing Education, 2017. 23(2): p. 175-183.

Lee, S.J., and Park, J. Y. (2018). The effects of grit and stress on nursing student's adjustment to college life, Journal of Digital Convergence, 16(2), 269-276.

Kang, S.W. College life adjustment, grit, and self-leadership among nursing students. Journal of the Korean Data Analysis Society, 2017. 19(4): p. 1793-1803.

Jung, M.R., and Jeong, E. Effects of academic stress, academic self-efficacy and major satisfaction in nursing student on grit. Journal of the Korea Contents Association, 2018. 18(6): p. 414-423.

Duckworth, A.L. Grit: The power of passion and perseverance. 2016, New York: Simon and Schuster.

Kim, M.S., et al., The environmental factors affecting students' grit scores and their differences across sex and grade. Journal of Learner-Centered Curriculum and Instruction, 2015. 15: p. 297-322.

Lee, W.W.S. Relationships among grit, academic performance, perceived academic failure, and stress in associate degree students. Journal of Adolescence, 2017. 60: p. 148-152.

Table 1 General characteristics of participants

\begin{tabular}{|c|c|c|}
\hline Variables & n & \% \\
\hline Gender & & 16.1 \\
\hline Male & 44 & 83.9 \\
\hline Female & 229 & \\
\hline Grade & & 25.3 \\
\hline 1st & 69 & 22.3 \\
\hline 2nd & 61 & 25.6 \\
\hline 3rd & 70 & 26.7 \\
\hline 4th & 73 & \\
\hline Clinical practice experience & 130 & 47.6 \\
\hline No & 143 & 52.4 \\
\hline Yes & & \\
\hline
\end{tabular}


Table 2 Participants' grit score

\begin{tabular}{|c|l|c|}
\hline \multicolumn{2}{|c|}{ Variables } & Mean (SD) \\
\hline \multicolumn{2}{|c|}{ Total grit } & $3.27(0.58)$ \\
\hline Grit sub-factor: Consistency interest & $3.13(0.70)$ \\
\hline Item 1 & New ideas and projects sometimes distract me from previous ones. & $2.91(0.86)$ \\
\hline Item 2 & $\begin{array}{l}\text { I have been obsessed with a certain idea or project for a short time } \\
\text { but later lost interest. }\end{array}$ & $3.24(0.92)$ \\
\hline Item 3 & I often set a goal but later choose to pursue a different one. & $3.17(0.91)$ \\
\hline Item 4 & $\begin{array}{l}\text { I have difficulty in maintaining my focus on projects that take more } \\
\text { than a few months to complete. }\end{array}$ & $3.21(0.99)$ \\
\hline Grit sub-factor: Perseverance of effort & $3.40(0.65)$ \\
\hline Item 5 & Setbacks don't discourage me. & $3.46(0.80)$ \\
\hline Item 6 & I am a hard worker. & $3.56(0.89)$ \\
\hline Item 7 & I finish whatever I begin. & $3.46(0.89)$ \\
\hline Item 8 & I am diligent. & $3.12(1.03)$ \\
\hline
\end{tabular}

Table 3 Differences in grit score according to participants' general characteristics

\begin{tabular}{|c|c|c|c|c|c|c|}
\hline \multirow{3}{*}{ Variables } & \multirow{2}{*}{\multicolumn{2}{|c|}{ Grit }} & \multicolumn{4}{|c|}{ Grit sub-factors } \\
\hline & & & \multicolumn{2}{|c|}{ Consistency interest } & \multicolumn{2}{|c|}{ Perseverance of effort } \\
\hline & Mean (SD) & $t / F(p)$ & Mean (SD) & $t / F(p)$ & Mean (SD) & $\mathrm{t} / \mathrm{F}(\mathrm{p})$ \\
\hline \multicolumn{7}{|l|}{ Gender } \\
\hline $\begin{array}{c}\text { Male } \\
(\mathrm{n}=44)\end{array}$ & $3.63(0.57)$ & \multirow{2}{*}{$\begin{array}{c}4.684 \\
(<0.001)^{*}\end{array}$} & $3.51(0.76)$ & \multirow{2}{*}{$\begin{array}{c}3.922 \\
(<0.001)^{*}\end{array}$} & $3.75(0.59)$ & \multirow{2}{*}{$\begin{array}{c}3.978 \\
(<0.001)^{*}\end{array}$} \\
\hline $\begin{array}{c}\text { Female } \\
(\mathrm{n}=229)\end{array}$ & $3.20(0.56)$ & & $3.06(0.67)$ & & $3.33(0.64)$ & \\
\hline \multicolumn{7}{|l|}{ Grade } \\
\hline $\begin{array}{c}1 \text { st } \\
(n=69)\end{array}$ & $3.27(0.58)$ & \multirow{4}{*}{$\begin{array}{c}0.208 \\
(0.891)\end{array}$} & $3.19(0.70)$ & \multirow{4}{*}{$\begin{array}{c}0.336 \\
(0.799)\end{array}$} & $3.36(0.65)$ & \multirow{4}{*}{$\begin{array}{c}0.287 \\
(0.835)\end{array}$} \\
\hline $\begin{array}{c}\text { 2nd } \\
(n=61)\end{array}$ & $3.24(0.49)$ & & $3.08(0.65)$ & & $3.40(0.57)$ & \\
\hline $\begin{array}{c}3 r d \\
(n=70)\end{array}$ & $3.24(0.60)$ & & $3.11(0.75)$ & & $3.37(0.67)$ & \\
\hline $\begin{array}{c}4 \text { th } \\
(n=73)\end{array}$ & $3.31(0.62)$ & & $3.15(0.71)$ & & $3.46(0.71)$ & \\
\hline \multicolumn{7}{|c|}{ Clinical practice experience } \\
\hline $\begin{array}{c}\text { No } \\
(130)\end{array}$ & $3.26(0.54)$ & \multirow{2}{*}{$\begin{array}{c}-0.218 \\
(0.827)\end{array}$} & $3.14(0.68)$ & \multirow{2}{*}{$\begin{array}{c}0.069 \\
(0.945)\end{array}$} & $3.38(0.61)$ & \multirow{2}{*}{$\begin{array}{l}-0.461 \\
(0.645)\end{array}$} \\
\hline $\begin{array}{c}\text { Yes } \\
(143)\end{array}$ & $3.27(0.61)$ & & $3.13(0.73)$ & & $3.42(0.69)$ & \\
\hline
\end{tabular}

